\title{
Managing Ethical Dilemmas under Stressful Economic Circumstances among Journalists in Northern Ghana
}

\author{
By Amin Alhassan ${ }^{*} \&$ Muhammed Abdulai ${ }^{*}$
}

\begin{abstract}
This article explores the management of ethical dilemmas in stressful economic circumstances among journalists in the three Northern Regions of Ghana. It analyses the experiences of journalists during difficult ethical moments. In-depth interviews were conducted with a total of 30 working journalists, drawing 10 from each of the three northern regions. These are the Upper West, Upper East and Northern Regions. The study revealed that in practice, rather than working with the normative ethical framework defined by the codes of ethics of the Ghana Journalists Association, journalists are influenced by context-based pragmatism and their conduct is very much influenced by economic realities of satisfying basic needs. Again, the study revealed that most Ghanaian journalists understand the idealism of ethical norms and are very much aware of the GJA code of ethics, but see the practicability of the code as problematic. We recommend that the GJA increases its advocacy role on improving the working conditions of its members. It should also facilitate continuous professional development programs on media ethics in the changing media landscape. Improved working conditions and continuous professional development programs can assist its members in managing ethical dilemmas in stressful economic and social circumstances.
\end{abstract}

Keywords: ethical dilemmas, ethics, Ghana, journalism, stressful economic circumstances.

\section{Introducing the Problem}

In recent times, the Ghanaian media landscape has witnessed some dramatic news of job cuts, and voluntary retrenchment of media workers. Media General, owners of the TV3 Network, has between August and October 2018 reduced its staff by about 125, notably affecting its Onиa FM and 3FM units. GN Media and $T V$ Africa have all, in recent times, reduced their workforce for the poor performance of their media industries and this has attracted the attention of the Ghana Independent Broadcasters Association (GIBA) ("GIBA to meet labour unions," 2018). This national trend is in keeping with international trends. What makes the Ghanaian experience remarkable is that the global trend is just beginning to affect the local media industry. In the wake of these developments, job insecurity in an already precarious media labour market is likely to affect the quality of professionalism among journalists in Ghana, with dire consequences in northern Ghana, where the media economy is in a distressed state due to low advertising market (Alhassan, Odartey-Wellington, \& Amadu, 2018). It is against this backdrop that we undertook a study on how journalists manage ethical dilemmas under stressful economic circumstances.

\footnotetext{
*Associate Professor of Communication, University for Development Studies, Tamale, Ghana. ${ }^{\dagger} \mathrm{PhD}$ Candidate, School of Governance, Law and Society, Tallinn University, Estonia and Lecturer, University for Development Studies, Tamale, Ghana.
} 
Media and communication ethics are important in promoting transparent and accountable governance in modern democratic societies. The media and journalists in any country are believed to be a strong ally in shaping and forming the opinion of the population. In light of this, ethical questions are therefore tied to the core practices of journalism, and journalists are required to make sound moral decisions and judgements in their daily journalistic practices. However, quite often, journalists are confronted with dilemmas out of which they have to make decisions.

Professional associations with defined codes of ethics are self-regulatory mechanisms aimed at disciplining members to act within the law and moral norms of a given society. As Andrew Puddephatt puts it: "Self-regulation preserves independence of the media and protects it from partisan government interference" (Puddephat, 2011, p. 12). It is in this regard that the GJA has been active in reminding its members of the ethical boundaries of their practices. In a recent rare case where a member was proven to have used blackmail to extort five million Ghana cedis from the head of a utility service provider in Ghana in a bid to kill a story, the President of GJA took the initiative to report the matter to the Ghana Police for further investigation ("Journalist who demanded GHC5m," 2018). The vigilance of the GJA on matters of ethics speaks to an increasing national and public attention on moral governance of media practice.

Among researchers, increasing attention has been drawn on the issue of ethical dilemmas in journalism and the corrupting influence of inducements. In the context of Africa, previous studies on media and communication ethics have focused on newsroom practices, journalism ethics, "soli" (brown envelop) among others (Alhassan \& Abdulai, 2019; Karikari, 1996; Hasty, 1999; Hasty, 2001; Kasoma, 2009; Chari, 2007; Frère, 2001; Berkeman \& Shumovary, 2003; Skjerdal, 2010; MFWA, 2014). Again, a lot of these studies have been devoted to the potential negative effects of unprofessional journalistic practices and how it threatens development reporting (Kasoma, 2009; Diedong, 2008). For instance, through case study, historical summaries and illustrations, Berkeman and Shumovary (2003) discussed ethical dilemmas and challenges on online media practices such as: sourcing, intellectual property rights and conflict of interest in Zimbabwe. The study by Berkeman \& Shumovary, highlighted ethical dilemmas faced by media professional who were engaged in online media practices in Zimbabwe. Again, Lohner, Banjc, and Neverla (2016) revealed that in Kenya, environmental journalists and editors are often faced with the dilemma of whether to pursue a story which they know is of public interest, but critical to an influential source and therefore risk being fired, or ignore the story and negate their professional obligation.

In Ghana, following the liberalization of the media landscape, the media are now quite diverse and pluralistic (Alhassan, 1998). As a result, the growing public perception is that journalistic conducts are often unethical and unprofessional. This has resulted in a growing body of empirical and critical studies on journalism and ethics in the media (Agbemenu \& Tandoh, 2015; Diedong, 2006). For instance, in his study of the "Impact of Brown Envelop Journalism on Journalistic Practice in Zambia and Ghana," Kasoma (2009) applied both surveys and in-depth interviews 
and analyzed the rampancy of the phenomenon in the two countries, and how journalists perceived the practice. The study revealed that brown envelope journalism was pervasive in both Ghana and Zambia.

While these bodies of research (Berkeman \& Shumovary, 2003; Lohner et al., 2016; Kasoma, 2009) presented an excellent overview of the negative effects of unprofessional media practices, there is paucity of study on the ethical dilemmas journalists are faced with on their quest for making sound moral decisions in stressful economic circumstances in Africa. We define "stressful economic circumstances" as moments where an individual is faced with a spectre of want as he or she is challenged with meeting the basic requirements or basic needs of life for himself or herself and dependents.

For instance, a journalist with a monthly salary of about two thousand cedis (about 450 US dollars) undertakes an investigation of a banking fraud leading to a big story in which some senior bankers are involved. When a senior banker discovers that the publication of the story could end his career, he makes an inducement offer of fifty thousand cedis which is 25 times the journalist's monthly salary to kill the story. He or she turns down the offer, saying it is unethical and a corrupt practice. On reaching home, the journalist is confronted with disturbing news that his or her daughter has been admitted at the hospital and needs an emergency surgery to save her life. The hospital is demanding a five thousand cedis down payment before the surgery. The journalist is unable to take a loan from the bank and has no health insurance that covers the treatment. Under these circumstances, should the journalist revert to the offer from the banker to kill the story and be paid an amount which is ten times what is required to save the daughter's life? This illustration of "stressful economic circumstances" is a reallife story of a Ghanaian journalist. Facing a "limit situation," in a Freirean sense (Freire, 2005) as illustrated is not an uncommon experience for journalists working for low remunerations in northern Ghana. The question of whether to take the inducement or not, plays out daily in the lives of journalists and other media practitioners in northern Ghana. The figure of 2000 Ghana cedis monthly salary is national case scenario. Journalists working with private sector media in the northern part of the country earn an average of about 500 Ghana cedis, yet, it is commonly known that it is highly insufficient to cater for the basic needs of a nuclear family.

The main purpose of this study is specifically to seek an answer to the question: How do journalists rationalize how they make sound moral decisions under stressful economic circumstances in Northern Ghana? This study will contribute to the existing literature on media ethics and moral philosophy. This area of study is important because, on a daily basis, journalists are faced with decision making problems between two possible moral imperatives, deontological or situational, either of which may have their justification. 


\section{Conceptualizing Ethics and Ethical Dilemmas in stressful Economic Circumstances}

Many attempts have been made to define ethics (Bentham, 2009; Fletcher, 1966; Karashani \& Rioba, 2002). However, it can sometimes appear as nebulous and controversial as morality itself. To this end, Sanders (2003), defines ethics as the study of the grounds and principles for right and wrong human behavior. This implies a critical reflection and self-confrontation with the moral choices or actions that individuals make in their everyday activities. For instance, making a value judgment about the circumstances under which to accept a bribe and kill a story, and save a daughter's life because one is in a financially stressful situation, or turning down an offer, saying it is unethical and a corrupt practice because one wants to be objective and truthful in the discharge of his or her duty as a journalist.

Again, ethics deals with the problem of choosing between different domains of life and assumes there is a real choice between different kinds (Karashani \& Rioba, 2002). This means that the study of ethics is not only limited to what constitutes good or bad actions, but making value judgments about individual actions. In addition, Frost (2015) asserts that ethics is a method of examining morality that permits decisions to be made when individuals are confronted with particular issues bordering on moral dilemmas. As mentioned early, journalism practice involves daily encounters with a range of issues that present ethical dilemmas for journalists who have to make sound ethical decisions. In connection with this, Merrill (2004) defines an ethical dilemma to mean a situation in which a difficult choice has to be made between two actions which present transgressing moral principles, either of which is acceptable. Again, Karashani \& Rioba (2002) observed that journalists have contractual duties as employees; professional duties as journalists; duties of responsibility to source, and the public. In all these contractual duties, the journalist's obligation to choose how he/she performs his/her duties may depend on the interest of the journalist or whom he/she feels most loyal towards. Similarly, Hulteng (1976) noted that journalists are serving multiple interests, thus, the public interest, the journalist's self-interest and the interest of the public and these multiple services inevitably lead to conflict of interest. This is partly because human beings by nature are selfish and egoistic. In this context, the egoistic agenda of some journalists tend to override their professional responsibility to offer honest and dedicated service to the public on whose behalf they enjoy the privileges of the fourth estate of the realm.

Moreover, Owusu (2012) concludes that journalists have professional responsibility to stick to the truth and bound by the professional codes that are formed to uphold the truth. In this regard, journalists are supposed to adhere to the highest ethical standards in carrying out their professional duties. In addition, Retief (2002) noted that most societies trust that journalists would not betray the professional codes that are formed to uphold the truth. However, being human, these professional codes of conducts are sometimes betrayed by some journalists. In connection with this, Nasidi (2016) revealed that journalists in Nigeria sometimes behaved contrary to the professional duty to uphold the truth. The study attributed this to the complexities of Nigeria as a country, with its multiplicity of 
ethnic groups, culture and religions, which turn to make journalists from opposite sides of these divides, oppose each other in their practice and generating conflicting journalistic values and ethical judgements.

In the context of Ghana, article 10 of the GJA code of ethics asserts that "no journalist shall solicit or accept bribes or any form of inducement to influence his/her professional duties" (GJA Code, 2017, article 10). This implies that the GJA codes prohibit either accepting or demanding bribes to kill a story, no matter the circumstance. However, low salaries for media staff are likely to breed corruption in the Ghanaian media. In a situation where journalists have low salaries and fear losing their jobs, being ethical in reporting can be perceived as a lesser priority than making money and complying with what is expected from them by their superiors.

Instructively, ethical theories are to be the foundation upon which ethical solutions are harnessed to the overriding difficulties that are encountered by individuals, journalists and other professional groups. These theories have been the theoretical underpinnings which provide guidelines concerning how to live and act in an ethical manner. For instance, Nasidi (2016) enumerated some factors which are accountable for unethical journalistic practices which included: poor pay, technical knowledge, conflict of interests, and ownership pattern among others. These highlighted factors arguably are pervasive, particularly in many third world countries, leading to circumstances under which the professionalism of journalists might be compromised.

Furthermore, counter to both individual and institutional influences are the influence emanating from cultures and values. It can be fathomed that journalists are part and parcels of a context under which they live and work which is submerged under distinct cultures which turn to resonate and reflect their view point. This is discernible in the differences between journalists from democratic jurisdictions and those from authoritarian states. They both wear different ethical compasses and what is regarded as ethically approved way of conduct may appear in a different light in another context.

\section{Ethical Theories and Their Applications in Ethical Dilemmas in Stressful Economic Circumstances}

Theoretically, different scholars have classified ethics differently. The most common classifications are: deontological ethics, teleological/ consequential ethics and individualistic or subjective ethics (Sanders, 2003; Barcalow, 1994; Merrill, 2004). In this study, we are going to focus on normative ethical theories and their applications in the context of ethical dilemmas in stressful economic circumstances in journalistic practices in Northern Ghana. Some of the ethical theories discussed in this study are: teleological/consequential ethical principles (situational and utilitarian ethical principles), where an action is judged based on its consequences, and the deontological ethical principle (categorical imperative), where the emphasis is placed on the notion of duty (Brown, 2011; Sanders, 2003). 
To start with, one consequential ethical theory is situational ethics. Situational ethics has been extensively discussed in Joseph Fletcher (1966) book, Situational ethics: the new morality. The theory holds that an action is considered ethical if it creates the greatest amount of love at the end of the action (Fletcher, 1966). Situational ethics is against absolutism (Titus, Smith, \& Nola, 1995; Fletcher, 1966). Thus, the application of codes of ethics, rules, and adherence to general standards with few exceptions. In this context, situational ethics does not have absolute norms or standards, but a non-legalistic flexible application of the standards to each individual situation (Titus et al., 1995). Relating this philosophy to the study, the ethical value of reverting to the offer from the banker to kill the story in order to pay for an emergency surgery to save the journalist daughter's life, and rejecting the offer from the banker to kill the story because it is considered unethical and a corrupt practice would be determined based on the situation, but not on the legalistic application of ethical standards or norms that are logically consistent with ethical codes, rules and regulations. Similarly, Fletcher (1966) further noted that an action is good so long as it brings love to the actors, or the end must bring loving results to the actors. In this regard, when measuring an ethical decision or situation, one must consider the desired end, the means available, the motive for acting and the foreseeable consequences (Fletcher, 1966). For instance, if reverting to the offer from the banker to kill the story in order to pay for an emergency surgery to save the life of the journalist's daughter will bring love to the journalist, the banker and the society, then accepting the bribe or inducement under the circumstances could be considered a good ethical decision. On the other hand, if rejecting the offer from the banker to kill the story and allowing his/her daughter to suffer from the sickness would bring love to the journalist, the banker and the society, then rejecting the offer would be considered a good ethical decision or judgement.

We find the principles of utilitarianism relevant to this study. The utilitarianism theory considers ethics as that which is designed to create the greatest good for the maximum number of people (Bentham, 2009; Rosen, 2003; Moore, 1903). Jeremy Bentham sets out "the principle that the greatest happiness of the greatest number is the measure of right and wrong" (Sanders, 2003, p. 32). Similarly, J. S. Mill is also credited for the principle of utility and the greatest happiness (Barcalow, 1994). Mill shared the view that the greatest happiness of the greatest number should be the determining principles of human action. In this context, an action is considered right if it promises the most happiness to the greatest number of people (Barcalow, 1994). In connection with the case under investigation, on the one hand, if reverting to the offer from the banker to kill the story in order to pay for an emergency surgery to save the life of the journalist's son would promote the greatest happiness of the greatest number of people, accepting the bribe under the circumstances could be considered a good ethical decision or judgement. On the other hand, if rejecting the offer from the banker to kill the story and allowing his/her son to suffer from the sickness would not promote the greatest happiness of the greatest number of people, rejecting the offer could be considered a bad ethical decision or judgement. 
Furthermore, another consequential ethical principle is ethical egoism. According to the principle of egoism, "human beings are motivated purely by self interest in all their actions" (Barcalow, 1994, p. 54). This implies that what is considered a good ethical judgment ultimately rests on self-interest. The principle of egoism is opposed to ethical altruism. For the ethical altruists, the principle is that human beings should not be selfish towards the welfare of others (Barcalow, 1994). In relation to the ethical egoism principles, if reverting to the offer from the banker to kill the story in order to pay for an emergency surgery to save the life of the journalist's son will promote the self- interest of the journalist against the interest of the society, accepting the bride under the circumstances could be considered a good ethical decision to the journalist. Again, if rejecting the offer from the banker to kill the story and allowing his son to suffer from the sickness would not promote his/her self-interest, rejecting the offer would be considered a bad ethical decision.

Deontological ethics is opposed to the teleological/consequential approach to ethics. The deontologists disagree that results or consequences should be the only measure of whether an act is ethical or unethical (Rosen, 2003; Sanders, 2003; Barcalow, 1994). In this regard, deontologists believe in rules or principles based on reason, which provide stability in the moral order (Sanders, 2003). To this end, the German Enlightenment philosopher Emmanuel Kant developed his theory of the categorical imperative which is ascribed to the deontological ethical philosophy (Sanders, 2003; Barcalow, 1994). The principle of categorical imperative holds that: act only according to the maxim by which you can, and at the same time will that it should become a universal law for all rational beings (Sanders, 2003. p. 31). This implies that human beings should act on the premises that the choices one makes for oneself could become universal law for all rational beings. In view of this, the moral law should come from the individual and the will to act should be consistent until it becomes a universal law. In other words, the action of the individual should be based on the will of the individual to act good no matter the circumstances and consequences. Applying this theory to this study, it will imply that, if reverting to the offer from the banker to kill the story in order to pay for an emergency surgery to save the life of the journalist's daughter would be considered by the journalist as a good moral conducted, and would promote that principle as a universal maxim, it would be considered an ethical decision. Again, if rejecting the offer from the banker to kill the story and allowing his son to suffer from the sickness would not be promoted as universal principle, then it would not be considered as a good ethical decision.

In addition, the principle of categorical imperative asserts that "a person must always be treated as an end and not merely as a means" (Sanders, 2003, p. 31). This implies that all humanity is to be treated with due respect and dignity because human beings are rational beings, with the ability to think, autonomous and are their own ends. In other words, human beings should be treated as an end in themselves, but not as a means to an end, because human beings exist in themselves. Relating this to the study, it implies that, if reverting to the offer from the banker to kill the story in order to pay for an emergency surgery to save the life 
of the journalist's daughter is considered as an end, then accepting the offer from the banker and killing the story could be considered a good ethical decision.

\section{Research Design: Selection of Interviewees}

Ghana has ten administrative regions, three of which are located in the Northern Savannah Ecological Zone. These three regions are Upper West, Upper East and Northern Regions. They are also noted as the economically depressed regions of Ghana. We adopted purposive sampling technique in selecting our interviewees. According to Yin (2003), purposive sampling is the deliberate choice of an informant due to the qualities the informant possesses. In view of this, all the participants were purposively selected for the study. In terms of inclusion and exclusion criteria, we included journalists who were willing to provide information by virtue of their knowledge or experience on the topic. Again, we excluded journalists who were not experienced enough in the practices of journalism, and were not willing to take part in the study.

In all, we interviewed 30 journalists in the three regional capitals of Northern Ghana (Tamale, Bolgatanga and $\mathrm{Wa}$ ). In each region, ten journalists were interviewed. Besides, the participants included nineteen (19) males and eleven (11) females, between 25-55 years of age at the time of the interviews. The journalists who were interviewed were given copies of the interview-guide (see Appendix) to go through the questions before the start of the interviews. We asked questions based on the topics in the interview-guide, while research-participants responded accordingly. The researchers were not obliged to follow the interview-guide strictly; they could sway from one topic to another, but always returned to follow the trajectory. Every interview session took between 45 minutes to one hour. All the he interviews were conducted in June 2018 and were audiotaped. Below is a diagrammatical representation of the study participants (Table 1).

In any research, concerns about guaranteeing confidentiality, anonymity, nonidentifiability and non-traceability of the participants are paramount to ensuring the validity and quality of the data (Denzin \& Lincoln, 1994). In light of this, the purpose of the study was explained to all the participants. The estimated duration of the interview was indicated to each of the participants, and each one was also reminded that participation in the study was voluntary. Participants were given the option to withdraw from the study at any stage, should they so wished. Similarly, raw data in the form of conversation transcripts were treated in a way that protected the confidentiality and anonymity of the participants. Where a participant discontinued the interview, a replacement was found to make up the ten respondents per region. 
Table 1. Diagrammatical Representation of the Study Participants

\begin{tabular}{|c|c|c|c|c|}
\hline $\begin{array}{c}\text { Code for study } \\
\text { Participants }\end{array}$ & Sex & $\begin{array}{c}\text { Years of } \\
\text { Experience }\end{array}$ & $\begin{array}{l}\text { Ownership of the } \\
\text { Media Institution }\end{array}$ & $\begin{array}{l}\text { Education/ } \\
\text { Training }\end{array}$ \\
\hline $\mathrm{JB}$ & $\mathrm{M}$ & 6 & Public & Journalism \\
\hline $\mathrm{JC}$ & $\mathrm{M}$ & 5 & Private & Media Management \\
\hline $\mathrm{RC}$ & $\mathrm{M}$ & 12 & Public & Communication Studies \\
\hline RB & $\mathrm{F}$ & 5 & Public & Media Management \\
\hline $\mathrm{SC}$ & $\mathrm{M}$ & 2 & Private & Communication Studies \\
\hline SU & $\mathrm{F}$ & 7 & Public & Journalism \\
\hline SB & $M$ & 8 & Public & Journalism \\
\hline SK & $\mathrm{F}$ & 10 & Public & Journalism \\
\hline BB & $\mathrm{M}$ & 3 & Public & Communication Studies \\
\hline $\mathrm{CD}$ & $\mathrm{F}$ & 6 & Private & Journalism \\
\hline JU & $\mathrm{M}$ & 4 & Private & Journalism \\
\hline SL & $\mathrm{M}$ & 7 & Public & Journalism \\
\hline $\mathrm{HJ}$ & $\mathrm{F}$ & 4 & Public & Media Management \\
\hline JJ & $\mathrm{M}$ & 7 & Public & Journalism \\
\hline SP & $\mathrm{M}$ & 5 & Private & Journalism \\
\hline KL & $\mathrm{F}$ & 8 & Public & Communication Studies \\
\hline LL & $\mathrm{F}$ & 4 & Private & Journalism \\
\hline $\mathrm{AB}$ & M & 10 & Public & Media Management \\
\hline IK & $\mathrm{M}$ & 8 & Public & Journalism \\
\hline $\mathrm{BA}$ & $\mathrm{F}$ & 4 & Public & Journalism \\
\hline $\mathrm{MN}$ & $\mathrm{F}$ & 12 & Public & Media Management \\
\hline NM & $\mathrm{M}$ & 3 & Private & Public Relations \\
\hline VW & $\mathrm{M}$ & 5 & Public & Journalism \\
\hline GD & $\mathrm{M}$ & 2 & Private & Communication Studies \\
\hline WV & $\mathrm{F}$ & 10 & Public & Communication Studies \\
\hline RY & $\mathrm{M}$ & 6 & Public & Media Management \\
\hline $\mathrm{ZB}$ & $\mathrm{M}$ & 4 & Public & Journalism \\
\hline $\mathrm{YZ}$ & $\mathrm{M}$ & 3 & Private & Journalism \\
\hline $\mathrm{ZY}$ & $\mathrm{F}$ & 2 & Private & Media Management \\
\hline VB & $\mathrm{M}$ & 6 & Public & Journalism \\
\hline
\end{tabular}

Semi-structured face-to-face interview format was used. The interview method enables gathering of narratives and reflections of the journalists concerning the ethical dilemmas in stressful economic circumstances in their daily journalistic practices (Van Manen, 2018).

The interviews were transcribed verbatim, noting pauses, emphases, hesitations, and gestures, such as laughter. After the transcription, the data was coded through a process of open coding (Strauss, 1990). By this method, the authors read through the entire set of data several times and chunk the data into smaller meaningful parts, and label each chunk with a code. Again, the codes were used and compared with each new chuck of data with previous codes, so previous chunk data were labeled with the same descriptive codes. After all, the data were coded, the codes were selected and grouped by themes. After the 
themes were identified, classical content analysis technique was used to identify the most important themes (Bryman, 2004). The number of times each descriptive code occurred was ranked and the most important concepts were identified as the themes. The most important themes identified are:

1. Making sound ethical decisions under stressful economic circumstances in journalistic practice.

2. Situating Objectivity and truthful reportage in stressful economic circumstances.

\section{Findings and Discussion}

Our analysis identified situations where journalists were faced with ethical paradoxes in decision-making between two courses of action under stressful economic circumstances, and variations in the application of the set of agreed ethical principles under different situations and contexts. We present these findings below:

\section{Theme One: Making Sound Ethical Decisions under Stressful Economic Circumstances in Journalistic Practice}

Journalistic practice involves daily encounters with range of issues which might present ethical paradoxes, and could call for a quick, sound and rationalized ethical decision to be made by a journalist. To this end, the research participants were asked to share their experience concerning problematic situations which confronted them in the course of their professional practices. It turned out that most of the interviewees were quick to narrate their heroic moments of refusing an inducement and publishing the story. Here is a typical sample of such responses.

I have had an experience where I discovered a rot somewhere in Ghana. Ee... eeh... I was offered an opportunity to take a huge sum of money to kill a story. I was not working in isolation; I was working with the editorial team. So, when such things happened, you can't make a decision on your own, you need to talk to your editor, you need to talk to your immediate boss about what is going on. Eee,... In my case, I discussed the issue with my colleague to seek his opinion on the matter. After the discussion... he said to me... my brother, if you think the offer is good, why not take it? I was confused. It was against my ethics. However, I thought of my survival and financial problems. Eeeh, again, I weighed the magnitude of the crime against tarnishing the image of the person involved. Hmm... I thought of that, but I also thought of the ethical aspect of the case and the welfare of society. Eee...eeh for me to kill such a story, I damned my financial predicaments and published the story.

JB's response has highlighted a decision-making problem between two courses of action. That is, either to report the true story and remains in financial difficulty, or abrogates the professional code of journalism, kills the story for the entire society to suffer the consequences. In this regard, by adhering to the professional standards and rejecting the offer of money to kill the story implies 
that the decision of the respondent was informed by deontological ethical considerations. In this case, rejecting the offer of money to kill the story was meant to promote the greatest happiness of the greatest number of people in the society, but not based on his own egoistic or selfish interest. Similarly, another scenario was presented to the journalists to assess their level of commitment to truth and fairness. The story was presented this way, "...you went home from work and realised that your ward has been taken to the hospital for medical emergency. The doctors are demanding a GHS 5000.00 down payment before an emergency surgery can be done to save your ward from death. You simply do not have the money requested, but you still have the option of going back to accept the GHS 50,000.00 cedis from the banker to kill the story, will you take the offer?" In response, an interviewee, RB, expressed:

I have stated many times that based on the emergency nature of the case, I will take the money for the emergency surgery, but my story will never be different, the story will never be killed, it will be reported to reflect the reality.

The views expressed by interviewee RB do not only shed light on how situational factors can influence ethical decisions, but it has clarified how situational ethical values do not necessarily determine the legalistic application of ethical standards that are logically consistent with normative ethical principles such as truthfulness, fairness, objectivity among others. This understanding is in line with Fletcher's (1966) situational ethical principle, where an action is considered ethical if it creates the greatest amount of love at the end of the action. In this regard, by accepting to revert to take the offer from the banker in order to pay for an emergency surgery to save the journalist daughter's life could be based on the circumstances, and the greatest amount of love it could create to save his daughter's life. Contrary, the submission of the research participant is not in keeping with Kant's ethical principle of categorical imperative. This ethical principle holds that individuals should "act only according to the maxim by which you can at the same time will that it should become a universal law for all rational beings" (Sanders, 2003, p. 31). In this case, the decision by the research participant to take the money for the emergency surgery was not based on his own will to act well irrespective of the consequences of his decision on the survival of his daughter. In connection with the same question, interviewee SU narrated:

Normally, as a journalist you are supposed to provide voice for the voiceless and protect the interest of the society. So, why should I allow myself for an individual person to influence my passion with a gift? So, the issue of dropping the story and going back for the GHS 50,000.00 to save my ward from death is something I will not consider.

It can be inferred from the views expressed by the respondent that journalists are supposed to give voice to the voiceless, and their reportage should be 
linked to commitment to truth, fairness, objectivity and protection of the interests of the society. This understanding is congruent with the Golden Rule principle which stipulates that you should do to others as you will have them do to you (Sanders, 2003). Therefore, the decision of the study subject to reject the monetary offer and report the true story reflects the logical preposition that human beings are more likely to enjoy life if they contribute good deeds to protect the general interest of society rather than contributing negatively to society. In addition, by giving voice to the voiceless and protecting the general interests of the society, implies that the study subject might get the social and psychological comfort of having done something good for the society.

Furthermore, the study participants were asked to share their experiences about some of the bad ethical decisions they had made in the course of their journalistic practices. In relation to this, interviewee IK revealed:

Eehh... as a journalist, in the course of exercising your duty, there will be a point you will go out of line... eeh... I hope you understand? Ehh... in most cases, when you are invited for a programme... eeh... at the end of the day, you are offered a gift. But as a journalist you are not supposed to take bribe, you are not supposed to take gifts from event organizers. But..., you see..., very often we take gifts from event organisers. That is what we call soli or solidarity. I hope you understand. Just to show appreciation maybe for your T\&T. Ethically, we are not supposed to take soli.

It is noted from the above that some of the research subjects take gifts or bribes from event organizers, which conflicts with their professional journalistic principles to always respect and follow the code of ethics of the profession. In addition, it has also illuminated the culture of gift-taking, which is built and institutionalized into the economy of media coverage in Ghana. This practice is not in keeping with article 10 of the Ghana Journalist Association code of ethics (GJA), which stipulates that: "no journalist shall solicit or accept bribes or any form of inducement to influence his/her professional duties" (GJA Code, 2017, article 10). In light of this, the GJA code of ethics does not only prohibit the solicitation and acceptance of gifts from event organizers, but prohibits any conduct of journalists which are against the set of agreed principles that guide the conduct of journalism in Ghana.

In another development, a question was asked to ascertain how selfinterest could influence rational ethical decision-making under stressful economic circumstances, and interviewee GD explained.

Well... eeh... Self-interest is excessive greed. Do you get it? Everyone has interest, there is no human being in this world without an interest, but you see, your interest should not eat into your duties. In as much as you have interests, your interests should not override the interests of the general public. Eeh... Selfinterest can influence ethical decisions because we belong to associations, ethnicity, we have friends, families, and religion. Sometimes you are tempted to play down these things to be as fair as possible, but in most cases, you are consumed by these things. 
The above narration does not only cast light on the selfish nature of human beings, but it has also clarified how our membership to professional bodies, ethical ideals, values, families, friends, ethnicity and religion could influence our ethical judgements under problematic situations. In view of this, the inability of the research participant to act professionally in some cases could mean that the research participant does not recognize that balanced and truth reportage are preeminent values in journalistic practices. In addition, by acting unprofessionally in some cases due to the personal biases of the research participant (ethnic, religion, nationality and race) are not in tandem with the assumption of the deontological ethical principle of Kant which posits that "... a person must always be treated as an end and not merely as a means" (Sanders, 2003, p. 31). This implies that, no matter the circumstances, all humanity is to be treated with due respect and dignity, because human beings are rational beings and are their own ends.

\section{Situating Objectivity and Truthful Reportage in Stressful Social and Economic Circumstances}

This part of the analysis is concerned with how the respondents position their decisions pertaining to upholding objectivity and truthfulness when confronted with ethical decision making under stressful economic circumstances. A dominant perspective from the empirical data is the fact that some of the journalists consider society as their initial reference point in taking such decisions under such trying situations. The justification of this assertion is grounded in the expressed statement of interviewee JU.

Basically, journalism is about the interest of society, and so, whatever decision you want to make in the performance of your duty, you must consider the society first. It is the interest of the society (public interest) that is what often informed my decisions as to what to do.

Extracts from the interview data above seeks to drive home the fact that when confronted with difficult ethical judgements, some journalists take into consideration the implication of their decisions on the society defined as public interest. This is to be anticipated because it smacks of a dimension of collectivism, to which Africans are mostly classified into. In the northern part of Ghana, the views of the general society weigh too much on the conduct of an individual, on the grounds that individuals feel themselves part and parcel of the larger society. They reside and work in societies and the cultural worldview of their societies is what they reflect. Under the circumstances, an individual journalist will forgo his or her selfish interest, to serve the interest of the public. After all, the number one obligation of a journalist is to report the truth with an overriding loyalty to professional values, the public, and virtue, which prefer social improvement to personal interest (Nasidi, 2016). It can also be seen in the light of Fletchers' (1966) assertion that decisions and actions are 
good so long as their outcome engenders love and happiness to the actors. As such, the decisions of journalists that bring them happiness are those that represent the interest of the public.

In addition, our interview data has also highlighted elements of friends, relations and other actors within the society who try to exert some amount of influence under difficult ethical decision-making, to influence objective, accurate and truthful reportage. In connection with this, interviewee SP narrated:

My experience about ethical dilemmas... eeeh... eeh... You see this is a very difficult question. In most cases, you try to be objective and sincere to your work, but you are confronted with the powers within the society. People try to influence or stop you from reporting the true story. Friends, political figures, and even family members may try to influence you not to report the true story.

The above statement further demonstrated the fact that ethical practice is a complex process that is concerned with moral uprightness/fitness in a defined context. This assertion implies that the exercise of ethics borders on moral philosophies which are context-specific, because morality is many times subjective and depends on the situation and contexts. Ideally, practitioners must be independent in the exercise of their personal conscience and ethical inclinations, but, here, we are with influential elements within the social context trying to sway journalists off their ethical obligations.

Moreover, when the study participants were asked to share their views about situations where ethical values were violated, in response, interviewee SK stated:

Even though there are ethics, in practice we sometimes abuse these ethics, we go against these ethics to solve problems, you can't just say that because ethically, you are supposed to do this and there is something spoiling somewhere... eeh... and you will say, no, I won't do this because of ethics. Eeh... ethically, when you don't do it, you are not praised for that, ethics are not bidden by law, they are just supposed to guide you, but at any given time in practice, one will stray into some controversies, because if you don't break those ethics, you will not be able to get a good job done.

The submission of this interview participant revealed that ethics are not guaranteed unbreakable, though there may be cut and dried stipulations to guide the conduct of journalists. In this regard, at any point in time, ethics can be set aside in the interest of the public. This understanding is in keeping with the pragmatic ethical principle, which is concerned with the ultimate success, and with little concerned on the means to the success because the end justifies the means (Sanders, 2003). Even though researchers such as Merrill (2004) regarded this approach as Machiavellian, the fundamental responsibility is to provide truthful reportage as far as possible; how to achieve this, would be less important. The research participant demonstrated that you have to trespass upon the ethics, sometimes, in order to get a good job done. Here, the act of 
trespassing on the ethical guidelines becomes less important and achieving the ultimate goal (success) is of paramount importance to the journalist.

Similarly, in responding to the question on factors that can influence a journalist to make a bad ethical decision, an interviewee, SL, had this to say:

One of it is... eehh..., one of the key factors will be economical, yes, when your economic situation is so bad, it is very easy to make unethical decisions, if your professional knowledge is not that deep, you may be doing unethical things, but you wouldn't even know. So, ignorance is one, economic condition is two.

The statement above casts light on the economic factors and poor professional knowledge that could influence journalists to make bad ethical decisions. These economic factors and poor professional knowledge are to be expected, because it is argued that the growing economic pressures of today are generating precarious situations where only few journalists are up to the task of what is perceived to be their responsibilities (Merrill, 2004). In light of this, overriding profit motives are seen to be driving the course of editorial decisions and impeding the processes of quality, truthful and rightful ethical decisions. Also, poor technical knowledge will certainly be a recipe for unethical conduct, in that there will be lack of appreciation for the values and principles of the profession, leading to poor application of professional expertise, morals and values.

Intrinsic to taking ethical decisions under exacting circumstances are the integrity and personality journalists work to protect. This is where working journalists try to be honest and upright by holding on to what is right and truthful in the face of challenging situations. The foregoing has been expressed in the statement of interviewee AB:

What matters most in every job is integrity. In a case like this, I would consider it as a fraud. In journalism, you need to look at the number of people who will be affected by the activities of this particular bank. Do you get it? So, the picture has to go beyond you and don't forget that, as a journalist, the principle for your job is public interest. We are working in the interest of the general public, not in our interest. So, if you decide to take the 50,000.00 cedis and then let the story go, you are putting the lives and investments of over 100,000 people in danger, your story will stop a lot of harm or damage than is going to cause people investments.

Here, the study participant has considered his/her integrity, and as well as the expectations of a practicing journalist by the public. The evaluation led him to arrive at the conclusion that taking the 50,000 cedis and killing the story will be detrimental with far-reaching consequences to the public interests than an individual becoming complicit to the offer of inducement. This understanding resonates with the consequential ethical philosophy, which holds that the "consequences of an action are the key to assessing whether the action is ethical or unethical" (Sanders, 2003, p. 32). Therefore, upholding to the professional principle of objectivity, truthfulness, and balance reportage and rejecting the financial inducement because it is considered as a fraud and might 
have negative consequences on the society, sought to promote the greatest happiness of the greatest number of people in the society.

\section{Conclusion}

The paper explores ethical dilemmas and management in stressful economic circumstances among journalists in the three administrative regions of northern Ghana. Our analysis of the perspectives and opinions of 30 journalists across the three regions on ethical dilemmas and how ethical decisions are taken under stressful economic circumstances evidences the need to move beyond the holistic application of the western normative ethical principles in different circumstances and contexts. In light of this, we call for the application of contextual-based ethical principles by journalists in dealing with ethical dilemmas under stressful economic circumstances in Ghana.

Again, while journalists highlight their watchdog role over society and provide voice for the voiceless, the study revealed situations where journalists' personal interests and biases (ethnicity, religion, nationality, and professional associations) override the public interests in making ethical decisions under stressful economic circumstances. Based on this, the study concludes that there should be clear demarcations between personal interests and public interests, and comprehensive rules should be put in place to ensure that the public interests are always promoted by the journalists.

Finally, whiles the GJA code of ethics prohibits the solicitation and acceptance of inducements and bribes, the study revealed that a good number of Ghanaian journalists are not able to adhere to the GJA code of ethics. Therefore, the paper recommends that the GJA should organize regular training on media ethics and short professional courses for its members to improve upon their professional knowledge and skills on how to manage ethical dilemmas in stressful economic and social circumstances.

\section{Limitations of the Study and Future Research Directions}

The study has one major limitation. It did not cover the entire regions in Ghana, and that forms a major limitation of the study. Journalists, specifically, media practitioners and all those who work in the media industry in one way or the other, can be confronted with ethical paradoxes, for which making choices will be very eminent. We encourage researchers in the field of media and journalism to consider exploring the ethical dilemmas within the political systems and decisions concerning public welfare and parties' interests. Finally, another limitation associated with this study is courtesy bias, that is, the tendency of some of the interviewees to tell the interviewer what they think the interviewer might like to hear, or being afraid to admit to unethical behavior in a face-to-face interview. 


\section{Bibliography}

Agbemenu, S. K., \& Tandoh, J. (2015). The effect of "soli" on News Reportage in Ghana. International Conferences on Management, Communication and Technology (ICMCT), 3(1), 2026-6839.

Alhassan, A. (1998). Reception Analysis of Development News: Towards Evolving Appropriate News Genre. Journal of Development Communication, 9(10), 31-45.

Alhassan, A, Odartey-Wellington, F., \& Amadu, F. (2018). Commodification of development programming on radio in Northern Ghana. African Journalism Studies, 39(2). Retrieved from https://bit.ly/2UYhjSA.

Alhassan, A., \& Abdulai, M. (2019). Cultural and Moral Implications of Soli and Its Effects on Journalism in Northern Ghana. Journal of Media Ethics. Retrieved from https://bit.ly/2H2AWVU.

Barcalow, E. (1994). Moral philosophy. Theories and issues. New York, NY: ITP Publishing.

Bentham, J. (2009). An Introduction to the Principles of Morals and Legislation (Dover Philosophical Classics). Dover Publications Inc.

Berkeman, R. I., \& Shumovary, C. (2003) Digital dilemmas: Ethical issues for online media professionals. London: Blackwell Publishing.

Bryman, A. (2004). Social research methods. New York, NY: Oxford.

Brown, F. (2011). Journalism ethics: A casebook of professional conduct for new media (4th ed.). US: Marion street press.

Chari, T. (2007). Rethinking ethical issues in Africa Media. Africa Identities, 5(1), 3960.

Denzin, N. K., \& Lincoln, Y. S. (1994). Handbook of qualitative Research (2nd ed.). Thousand Oaks, CA: Sage Publications.

Diedong, A. L. (2006, July 23-28). Practicing journalism in a neo-liberated democratic culture: case study Ghana. Paper presented at IAMCR conference, Cairo, Egypt.

Diedong, L. A. (2008). Establishing journalistic standards in the Ghanaian Press. African Communication Research Journal, 1(2), 207-231.

Fletcher, J. (1966). Situation ethics: The new morality. Louisville, KY: Westminster John Knox Press.

Freire, P. (2005). Pedagogy of the oppressed. London and New York: Continuum.

Frère, M. S. (2001). Professional Ethics taken hostage by the political debate. In C. Ukpabi (Ed.), Handbook on Journalism Ethics. African case studies (pp. 49-64). Windhoek: The Media Institute for Southern Africa.

Frost, C. (2015). Journalism ethics and regulation (4th ed.). London: Routledge.

"GIBA to meet labour unions over mass layoffs at media institutions." (2018, September 4). MyJoyOnline. Retrieved from https://bit.ly/2SE63xB.

GJA Code (2017). The GJA code of ethics. Accra: Ghana Journalists Association. https://bit.ly/2PN89HC.

Hasty, J. (1999). Big Language and Brown Envelops: The Press and Political Culture in Ghana (Doctoral Dissertation). Duke University, Durham, NC.

Hasty, J. (2001). From Culture of silence to culture of contest: Hegemony, Legitimacy and the Press in Ghana. Journal of Cultural Studies, 3(2), 348-359.

Hulteng, J. N. (1976). The messenger's motives: Ethical problem of the news media. University of Oregon. New York, NY: Prentice Hall. 
Journalist who demanded GHC5m from ECG boss to 'kill a story' faces prosecution (2018, November 15), Ghanaweb. Retrieved from https://bit.ly/2JeCn58.

Karashani, F., \& Rioba, A. (2002). To Write or Not to Write: Ethical Concerns in Journalism. Dar es Salaam: Media Council of Tanzania.

Karikari, K. (1996). Ethics in Journalism: Case studies of practice in West Africa. Paris: Institut Panos.

Kasoma, T. (2009). Development reporting as a crumbling tower? Impact of brown envelope Journalism on journalistic practice in Zambia and Ghana. Global media journal - African Edition, 3(1).

Lohner, J., Banjc, S., \& Neverla, I. (2016). Journalistic Practices, Role Perception and Ethics in Democratisation Conflicts: Empirical Findings from Interviews with Journalists in Kenya, Egypt, Serbia and South Africa-Media Conflict and Democratisation. Working Paper. MeCoDEM. (Unpublished).

Merrill, J. C. (2004). Journalism Ethics: philosophical foundations for news media. USA: Pearson.

MFWA - Media Foundation for West Africa (2014). Media ethics monitoring final report 2014. Accra, Ghana. Retrieved from https://bit.ly/2GY7yib.

Moore, G. E. (1903). Principia Ethica. UK: Prometheus Books.

Nasidi, Q. Y. (2016). Media and ethics: Journalism ethics in Nigerian news media. IOSR Journal of Humanities and Social Sciences, 21(12), Ver. 3, 1-6.

Owusu, W. Y. (2012). The Ghanaian media landscape: How unethical practices of journalists undermine progress. Reuters Institute for the Study of Journalism Fellowship Paper, University of Oxford. Retrieved from https://bit.ly/2PKTAEm.

Puddephatt, A. (2011). The importance of self-regulation of the media in upholding freedom of expression. UNESCO CI Series, CI debates: communication and information, No. 9. Brasilia, Brasil.

Retief, J. (2002). Media Ethics: An Introduction to Responsible Journalism. Cape Town: Oxford University Press Southern Africa.

Rosen, F. (2003). Classical Utilitarianism from Hume to Mill. London: Routledge.

Sanders, K. (2003). Ethics and journalism. London, UK: Sage Publications.

Skjerdal, T. S. (2010). Research on brown envelope journalism in the African media. African Communication Research, 3, 367-406.

Strauss, J. C. (1990). Grounded theory research: procedures, canons, and evaluative criteria. Qualitative Sociology, 3-19.

Titus, H., Smith, M., \& Nola, R. (1995). Living Issues in Philosophy (9th ed.). London: Oxford University Press.

Van Manen, M. (2018). Researching lived experience: Human science for action sensitive pedagogy. London: Routledge.

Yin, R. K. (2003). Case Study Research: Design and Methods (3rd ed.). California: Sage Publications. 


\section{Appendix: INTERVIEW GUIDE}

\section{Ethical Dilemmas in Stressful Economic Circumstance among Journalists in Northern Ghana}

\section{Section A: Cases in Ethical Dilemmas}

1. How would you describe an ethical dilemma in journalism?

2. Tell me about your experience about ethical dilemmas in journalism.

3. What ethical challenges have you encountered as a journalist?

4. You are a journalist with a monthly salary of about two thousand cedis (GHS 2,000.00). Your investigations of a banking fraud led you to a big story in which some senior bankers are involved. When a senior banker discovers that you have an explosive story that could end his career, he makes you an offer of fifty thousand cedis (GHS 50,000.00), which is 25 times your monthly salary to kill the story. How will you manage the case as a journalist?

5. Alright, for those who rejected the offer of inducement to kill the story, what about this second part of the issue: You go home and realise that you ward has been taken to the hospital for medical emergency. The doctors are demanding a GHS $5,000.00$ down payment before an emergency surgery can be done to save your ward from death. You simply do not have the money requested, but you still have the option of going back to accept the GHS 50,000.00 cedis from the banker to kill the story, will you take the offer?

6. How would you describe a good ethical decision in journalism?

7. Tell me about unethical decisions in journalism.

8. What factors can influence a journalist to take a good ethical decision?

9. What factors can influence a journalist to take unethical decision?

10.In your opinion, in what way/ways can ethical dilemmas in journalism be resolved?

11.How can self-interest influence ethical decisions?

\section{Section B: Values and Principles of Journalism}

1. Who is a professional journalist?

2. What are some of the traits of a good journalist?

3. What are the ethical codes which guide the conduct of journalism in Ghana?

4. What are some of the professional principles of journalism?

5. How are the professional principles of journalism enforced in Ghana?

6. If there is one thing that you could change in journalistic practice in Ghana, what would it be? How would it make you feel?

7. Have you ever done undercover journalism?

8. What do you think are the ethical boundaries of undercover journalism?

9. Do you approve of the undercover journalistic style of Anas Aremeyaw Anas? 
